\title{
A Case of Brucellosis due to Brucella melitensis Isolated from Epidural Abscess
}

\author{
Epidural Apseden Izole Edilen Brucella melitensis’e Bağlı Bruselloz Olgusu
}

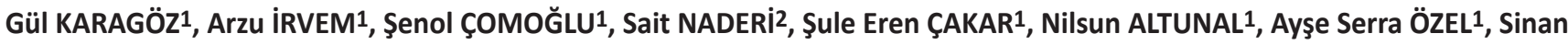 \\ ÖZTÜRK ${ }^{1}$, Ayten KADANALI ${ }^{1}$ \\ 1 University of Health Sciences, Ümraniye Training and Research Hospital, Clinic of Infectious Diseases and Clinical Microbiology, Istanbul, Turkey \\ 2 University of Health Sciences, Ümraniye Training and Research Hospital, Clinic of Neurosurgery, Istanbul, Turkey
}

Keywords: Bacterial infections, Brucellosis, treatment, epidural abcess, decompression surgery

Anahtar Kelimeler: Bakteriyel enfeksiyonlar, Bruselloz, tedavi, epidural apse, dekompresyon cerrahisi

\section{Dear Editor,}

Brucella species can cause a zoonotic infection brucellosis which may affect multiple tissues in the body including musculoskeletal system. Vertebral brucellosis is relatively common in the patients who have musculoskeletal involvement and should be diagnosed rapidly in the endemic regions. Early diagnosis and appropriate antimicrobial therapy combined with surgery are associated with an excellent prognosis; otherwise, delay in diagnosis increases the rate of morbidity and mortality ${ }^{[1]}$. Isolation of the microorganism from the tissue sample establishes the definite diagnosis and this is also necessary for the differential diagnosis. In this paper we aim to report a patient who presented to our clinic with spondylodiscitis and epidural abscess due to brucellosis.

A 46-year-old female patient admitted to our setting with fever for 4 months, chills, and sweating which was exaggerated at night. She also had complaints of lower back pain lasting 2.5 months in addition to fatigue, lack of appetite, and weight loss. She had history of stockbreeding and ate unpasteurized dairy products. On physical examination, her body temperature was $37.5{ }^{\circ} \mathrm{C}$, pain with local pressure was detected on the lumbar vertebrae, and her motor deficit grade was 2/5. The rest of general and neurological examinations were normal. The patient's laboratory test results were as follows: white blood cell

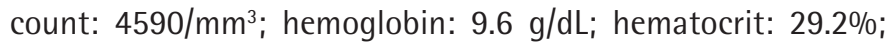
erythrocyte sedimentation rate: $95 \mathrm{~mm} / \mathrm{h}$; C-reactive protein: $5.9 \mathrm{mg} / \mathrm{L}$ (normal, 0 to $0.8 \mathrm{mg} / \mathrm{L}$ ); and a normal other blood biochemistry profile. The total serum protein, albumin, and globulin were also normal. There was no reversal of the albumin/ globulin ratio, and the Rose Bengal test was positive. The Wright agglutination test for Brucella was also positive at a titer of $1 / 2560$. However, the patient was not tested by the 2-mercaptoethanol. Magnetic resonance imaging (MRI) of the spine was consistent with the diagnosis of spondylodiscitis. The height of the Intervertebral disc between L5-S1vertebrae was decreased in addition to signal abnormality on the vertebral corpus and vertebral endplates in MRI (Figure 1, 2). An epidural abscess, $54 \times 22 \mathrm{~mm}$ in size, extending from the posterior of the $\mathrm{L} 5$ and $\mathrm{S} 1$ vertebrae to the paravertebral space and an abscess, $3 \times 2 \mathrm{~cm}$ in size, on the anterior prevertebral space were identified. Upon laminectomy, a purulent epidural and prevertebral mass were evacuated. After decompression, the motor deficit was improved and the pain was relieved. On the Gram stain of the

Cite this article as: Karagöz G, İrvem A, Çomoğlu Ş, Naderi S, Çakar ŞE, Altunal N, Özel AS, Öztürk S, Kadanalı A. A Case of Brucellosis due to Brucella melitensis Isolated from Epidural Abscess. Mediterr J Infect Microb Antimicrob. 2017;6:19. 


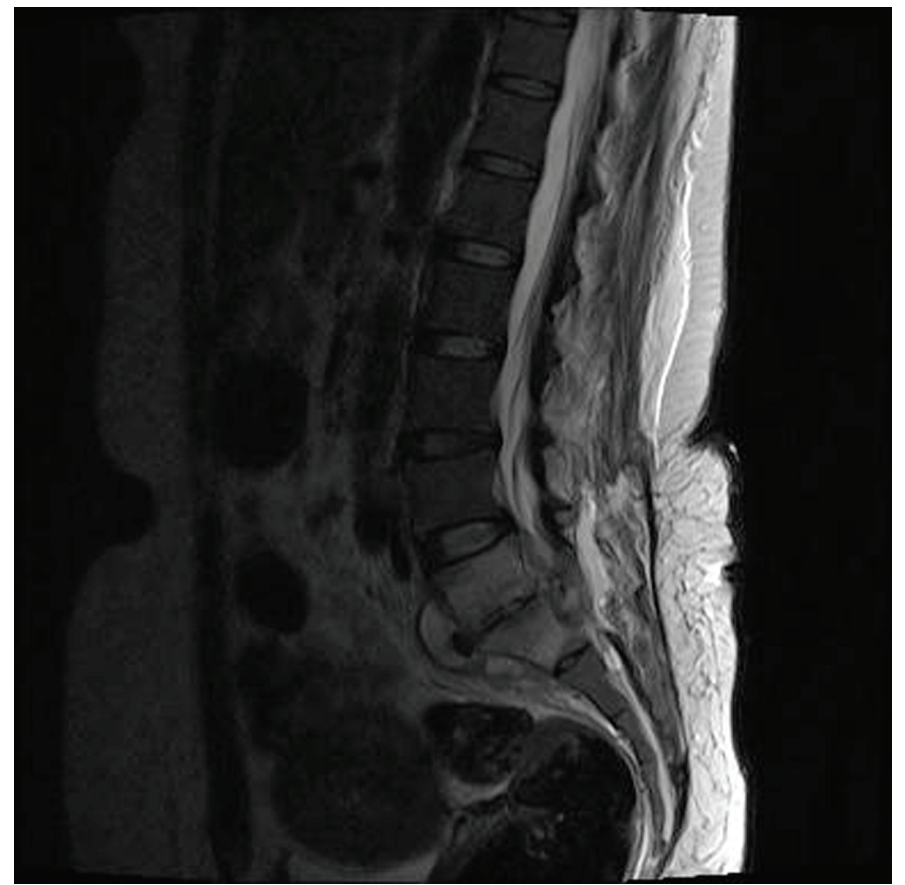

Figure 1. The sagittal plane magnetic resonance imaging view of the patient with spondylodiscitis at L5-S1

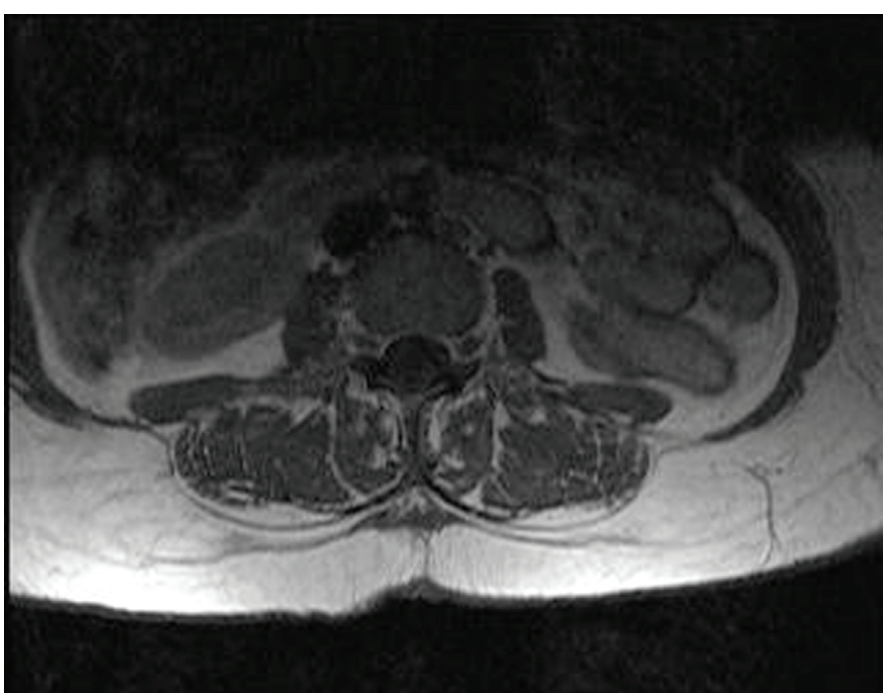

Figure 2. The axial plane magnetic resonance imaging view of the same patient

purulent material, Gram-negative coccobacilli were seen and the material was cultured on blood, eosin methylene blue and chocolate agar. All these plates were incubated at $37^{\circ} \mathrm{C}$. After three days, growth was seen on chocolate agar and the bacteria were identified as Brucella melitensis by automated VITEK 2 system (bioMerieux, France).

On the basis of these findings, she was diagnosed with L5S1 spondylodiscitis and epidural and paravertebral abscess due to Brucella melitensis. The patient was administered streptomycin ( $1 \mathrm{~g} /$ day) for 3 weeks along with doxycycline (200 $\mathrm{mg} / \mathrm{d})$ and rifampicin $(600 \mathrm{mg} / \mathrm{d})$ for 3 months.
After three months, the patient's condition gradually improved and the Wright agglutination test was positive at a titer of 1/160. All physical examination findings were normal. No complications were observed throughout the treatment. The symptoms of the patient disappeared and laboratory tests were normal at the end of the 3-month treatment period. Radiologic healing was also observed.

The skeletal system is commonly involved in brucellosis, however most important clinical involvement is spondylitis which is seen in 6-58\% of cases due to Brucella species ${ }^{[2,3]}$. Brucellosis is diagnosed definitively via isolation of Brucella species from blood or tissue samples in a laboratory, however, isolation of bacteria is not always possible ${ }^{[4]}$. Isolation of Brucella from an abscess or biopsy material provides conclusive evidence of Brucella infection, but this is achieved in less than 25\% of cases $^{[5]}$. In this situation, diagnosis can be performed based on a combination of serological techniques and clinical findings. Histological diagnosis is important and may be helpful in cases where cultures are negative ${ }^{[6]}$. Biopsy of the vertebral corpus or disc is necessary to successfully identify the causative agent. Thus, this procedure can guide an appropriate antibiotic treatment regimen ${ }^{[7]}$. It is necessary for the differential diagnosis of brucellar, pyogenic and tuberculous spondylodiscitis. Colmenero et al. ${ }^{[8]}$ also reported that if there was no clear evidence of causative agent, the vertebral biopsy should be performed. In the presented case we have isolated the bacteria for diagnosis using biopsy. In our case, surgical treatment was also necessary. Guerado and Cerván ${ }^{[9]}$ reported that there is the indication of surgical treatment if compression signs of a spinal cord, nerve root or dura mater are detected with MRI. In addition, surgical treatment is indicated in case of severe bone destruction and deformity causing spinal instability and anteriorly localized abscess larger than $2.5 \mathrm{~cm}$ according to the author. Although isolation of causative agent is difficult, we emphasize the importance of biopsy culture if non-invasive tests were insufficient.

The World Health Organization recommends combination therapy with tetracycline/doxycycline for 6 weeks and aminoglycoside (streptomycin for 2-3 weeks, gentamicin for 7-10 days ${ }^{[10]}$ as first-line treatment for spinal brucellosis. UluKilic et al. ${ }^{[3]}$ compared five major combination regimens (doxycycline, rifampicin, and streptomycin; doxycycline, rifampicin, and gentamicin; doxycycline and rifampicin; doxycycline and streptomycin; doxycycline, rifampicin, and ciprofloxacin) and they concluded that there was no difference between these combinations. There is no certain length of the treatment period, and the final criterion was an improvement in radiological findings. In our case, we continued the treatment until radiologic healing was observed. 
As a conclusion, brucellosis and the other infections of the skeletal system must be considered when evaluating patients with back pain, especially in endemic areas.

\section{Ethics}

Informed Consent: A consent form was filled out by all participants.

Peer-review: Externally and internally peer-reviewed.

\section{Authorship Contributions}

Surgical and Medical Practices: S.N., A.K., Ş.Ç., A.I., Ş.E.Ç., N.A., A.S..Ö., S.Ö., Data Collection or Processing: G.K., Analysis or Interpretation: A.B.F., G.K., Literature Search: S.N., A.K., Ş.Ç., A.I., Ş.E.Ç., N.A., A.Ş.Ö., S.Ö., A.B.F., G.K., Writing: G.K.

Conflict of Interest: No conflict of interest was declared by the authors.

Financial Disclosure: The authors declared that this study received no financial support.

\section{References}

1. Mackenzie AR, Laing RB, Smith CC, Kaar GF, Smith FW. Spinal epidural abscess: the importance of early diagnosis and treatment. J Neurol Neurosurg Psychiatry. 1998;65:209-12.
2. Harman $\mathrm{M}$, Unal $\mathrm{O}$, Onbaşi $\mathrm{KT}$, Kiymaz N, Arslan H. Brucellar spondylodiscitis: MRI diagnosis. Clin Imaging. 2001;25:421-7.

3. Ulu-Kilic A, Karakas A, Erdem H, Turker T, Inal AS, Ak O, Turan H, Kazak E, Inan A, Duygu F, Demiraslan H, Kader C, Sener A, Dayan S, Deveci O, Tekin R, Saltoglu N, Aydın M, Horasan ES, Gul HC, Ceylan B, Kadanalı A, Karabay O, Karagoz G, Kayabas U, Turhan V, Engin D, Gulsun S, Elaldı N, Alabay S. Update on treatment options for spinal brucellosis. Clin Microbiol Infect. 2014;20:75-82.

4. Kadanali A, Ozden K, Altoparlak U, Erturk A, Parlak M. Bacteremic and nonbacteremic brucellosis: clinical and laboratory observations. Infection. 2009;37:67-9.

5. Seidel G, Pardo CA, Newman-Toker D, Olivi A, Eberhart CG. Neurobrucellosis presenting as leukoencephalopathy: the role of cytotoxic T lymphocytes. Arch Pathol Lab Med. 2003;127:e374-7.

6. Gasbarrini A, Boriani L, Salvadori C, Mobarec S, Kreshak J, Nanni C, Zamparini E, Alberghini M, Viale P, Albisinni U. Biopsy for suspected spondylodiscitis. Eur Rev Med Pharmacol Sci. 2012;16(Suppl 2):26-34.

7. Quesnele J, Dufton J, Stern P. Spinal infection: a case report. J Can Chiropr Assoc. 2012;56:209-15.

8. Colmenero JD, Ruiz-Mesa JD, Sanjuan-Jimenez $R$, Sobrino $B$, Morata $P$. Establishing the diagnosis of tuberculous vertebral osteomyelitis. Eur Spine J. 2013;22(Suppl 4):579-86.

9. Guerado E, Cerván AM. Surgical treatment of spondylodiscitis. An update. Int Orthop. 2012;36:413-20.

10. Corbel MJ. Brucellosis in humans and animals. Geneva, Switzerland: World Health Organization Publications, 2006. 